y planteamientos paralelos en la reflexión en torno

a los mecanismos de canon y censura que hacen

diferentes disciplinas (Literatura Comparada,

Semiótica de la Cultura y Estudios de Traducción), propone una clasificación de estos mecanismos y señala una serie de prácticas dinamizadoras y posibles vías para su investigación.

PALABRAS CLAVE: canon, censura, institución, literatura, mercado, semiótica, sistema, traducción.

\title{
Canon y censura en los estudios de traducción \\ literaria: algunos conceptos y pautas metodológicas para la investigación
}

Maria Cruz Cristófol y Sel

Universidad de Cheikh Anta Diop de Dakar, Senegal
The current article advises parallel approaches and concepts around canon and censorship mechanisms on the analysis made by different disciplines (Comparative Literature, Semiotics of Culture and Translation Studies). It also suggests a classification of those mechanisms and, finally, it points at some dynamizing practices and researching lines for them. KEY WORDS: canon, censorship, institution, literature, market, semiotics, system, translation. 
En contra de la amnesia de la génesis, que es lo que origina todas las formas de ilusión trascendental, no hay antídoto más eficaz que la reconstrucción de la historia olvidada y oprimida que se perpetúa en esas formas de pensamiento aparentemente antihistóricas que estructuran nuestra percepción del mundo y de nosotros mismos.

$(\text { Pierre Bourdieu })^{\mathrm{I}}$

\section{CANON Y CENSURA, CARA Y CRUZ DE UNA MISMA MONEDA}

Frente a las definiciones tradicionales y comúnmente aceptadas de 'canon' y 'censura', en las que se identifica el canon con una serie de obras - los clásicos - que han permanecido en los altares literarios a lo largo de los siglos debido a supuestos valores estéticos universales, al don romántico —anacrónicamente impuesto- de la originalidad o a su excepcional tratamiento de temas considerados universalmente humanos ${ }^{2}$; y la censura sólo como una práctica política de — más o menos oculto — origen institucional para evitar intromisiones ideológicas en formas de gobierno de gran control — deudoras ambas de concepciones de poder y universalidad puestas en cuestión por las teorías críticas de la cultura-, parece más interesante para el estudio de la literatura y de la cultura apostar por alternativas menos trascendentales.

Afrontaré, pues, la cuestión del canon desde una perspectiva diferente de la de H. Bloom y otros críticos menos 'mediáticos', como R. Hughes, Allan Bloom o el erudito G. Steiner' integrantes del ala más conservadora (dado el apego que muestran respecto a nociones trascendentes acerca del valor literario) del debate sobre el canon —en palabras de Pozuelo4-

I (Bourdieu 2002: 49I) El subrayado es mío.

2 cfr. Bloom, H. El canon occidental.

3 cfr. Presencias reales, I99I

4 (Pozuelo 1995: 4) para situarme en tendencias que eligen la perspectiva histórica e ideológica, que son asimiladas por Bloom en la que despectivamente denomina «School of Resentment».

Sin entrar en críticas a las diferentes posturas del debate, ésta - la histórica e ideológica - me parece, como se verá a continuación, la perspectiva más fértil para los estudios empíricos de traducción.

A lo largo de estas páginas intentaré presentar, además, a modo de despuntes para la reflexión teórica y la aplicación metodológica al ámbito multidisciplinar de los Estudios de Traducción Literaria, que es el ámbito que nos ocupa, una serie de paralelismos que hacen asimilables algunas teorías de la Literatura Comparada y la Semiótica de la Cultura con los planteamientos surgidos en los últimos años en el seno de algunas tendencias de la Traductología y los Estudios Descriptivos de Traducción 5 .

5 Algunos ejemplos evidentes de estas tendencias paralelas son:

a) La desacralización del texto sagrado: El rechazo de la sacralidad inamovible de los textos canónicos y la tendencia a la inversión de cánones en ciertas tendencias actuales de la crítica literaria — algo a lo que los llamados Cultural Studies se han consagrado desde mediados de los años '6o: feminismos, teorías postcoloniales, teoría queer, East-West Studies ...-, que corre paralelo a la negación de la superioridad del texto original respecto al texto traducido - de segunda mano- en los estudios literarios de traducción. Esto, que no es más que parte de la excesiva orientación al texto de partida, es evidenciado por Hermans en su obra Manipulation of Literature, tal como expone Amparo Hurtado en Traducción y Traductología (Hurtado 200r:560-56I) y sienta uno de los presupuestos básicos de la «escuela de la manipulación» (Even-Zohar, Toury, Holmes, Hermans, Lambert, Lefevere, Bassnett...), que trataremos en el punto $\mathrm{I} .3$ del presente trabajo.

b) Interpretación - reescritura: La cuestión de la interpretación por parte de la crítica, que da lugar a la retextualización crítica (llamada 'acto evaluativo' por B. Smith y 'comentario' por F. Kermode) y a su vez a la dinámica del canon; frente a la cuestión de la interpretación para los estudios de traducción, que determina la re-textualización (reescritura, Lefevere) traductora y la dinámica del canon 
A partir de los textos de algunos de quienes las han formulado y analizado tanto en uno como en otro campo, de la Semiótica de la Cultura lotmaniana a la llamada «escuela de la manipulación» en Traductología ${ }^{6}$, me propongo extraer algunos conceptos y pautas metodológicas para el estudio del canon y la censura en los Estudios Descriptivos de Traducción.

Hay que añadir a esto que he decidido tratar la construcción del canon y el fenómeno de la censura conjuntamente por considerar que no son sino la cara y la cruz de una misma moneda, la acción y la reacción de un mismo movimiento; textos canónicos y textos censurados son - como también veremos- los efectos simétricamente opuestos de un movimiento de inclusión / exclusión en una zona privilegiada - canónica- del campo literario (P. Bourdieu), del polisistema literario (I. Even-Zohar) o del sistema semiótico literario (I. Lotman) a través de variados mecanismos más o menos institucionalizados? ${ }^{7}$.

Visto esto, se expondrán algunos de los principios teóricos y metodológicos de los EDT (Estudios Descriptivos de Traducción) a partir del texto programático de Gideon Toury, perspectiva desde la cual afrontaremos en un momento futuro la cuestión del canon y la censura en la práctica traductora.

entre fronteras lingüísticas (I. Even-Zohar).

6 Como puede verse, la selección de textos no es aleatoria - como no lo es jamás-, sino que obedece a nuestro claro interés por las perspectivas críticas, descriptivas y sistémicas.

7 Todo esto - eso sí- desde la asunción de una definición de la censura por extensión: como mecanismo de exclusión del campo o sistema literario para la que las concepciones clásicas del poder vertical —ejercido, administrado o impuesto desde un lugar identificado jerárquicamente en la parte superior de una pirámide- quedan relegadas exclusivamente a ciertos sectores de influencia — como la «censura institucional»— del campo y que — de forma global - aplica la lógica de redes foucaultiana, que incluye éste entre otros casos.

\section{EL CANON Y LA CRÍTICA}

El debate en torno al canon ha dado lugar a tantas polémicas, ha producido tanta literatura crítica desde que empezó a cuestionarse su legitimidad y ha resultado tan polarizado y, por ello, estéril que no es conveniente detenerse en ello, pero a modo de panorámica inicial, el volumen monográfico en la colección Eutopias «El canon en la teoría literaria contemporánea» (I995) de José Ma Pozuelo Yvancos puede introducir la teorías que más nos interesan.

Como dice Pozuelo, los resultados más satisfactorios en la investigación del funcionamiento del canon se han comprobado y pueden aún intuirse (pues queda mucho por hacer) en los estudios empíricos y en la «síntesis entre ideología y estética» que reside en un «esquema superior de naturaleza semiótica» (I995:8).

Talens $^{8}$, nos recuerda Pozuelo, denuncia y asume el carácter histórico y no inocente de la selección y construcción del canon,

En otras palabras, no se instituye para recuperar un pasado, sino para ayudar a constituir y justificar un presente. La elección del corpus sobre el que operar; el establecimiento de los criterios que hiciesen coherente la inclusión/ exclusión de obras y autores, así como la periodización y taxonomización del material no respondería, en consecuencia, a la existencia de una verdad exterior comprobable, sino a la voluntad de construir un referente a la medida, capaz de justificar la manera de vivir y de pensar el mundo por parte de la sociedad actual, a la que arroparía con el argumento de su autoridad (Talens 1994:I37, en Pozuelo I995:9)

8 Por evitar excedernos más en estas páginas, no hemos tratado aquí dos textos muy interesantes en los que Talens, desde su perspectiva semiótica-deconstructiva, habla de traducción («El sentido Babel») y de canon («Escritura contra simulacro»). Cfr. Referencias bibliográficas. 
Eso sí, sin que esta constatación suponga el abandono del interés por sus mecanismos de funcionamiento, que es precisamente lo que hace Walter Mignolo ${ }^{9}$, cuyo interés por la construcción del canon a través de las fronteras de las diferentes literaturas y cuyo análisis del concepto de Literatura Universal pueden hacerlo digno de atención para los investigadores no sólo de literatura comparada sino también de la traducción literaria. Entre sus conclusiones, es especialmente relevante aquella según la cual todo canon es regional, lo cual entronca con la crítica de Talens previamente expuesta y pone en evidencia la falta de rigor de las teorías universalistas de bases eurocéntricas.

Es imprescindible, por tanto, tener en cuenta ambos aspectos en un mismo eje de tensión espacio-tiempo. Para un análisis de las construcciones históricas del canon sería, pues, más ajustado a las dinámicas del sistema hablar no de 'canon', sino de 'cánones' o de 'sistemas', y establecer para su estudio ese eje formado por dos aspectos:

I) el marcado por Talens: el eje histórico o diacrónico, es decir, ¿cuáles eran, y por qué razones, en una determinada sección del eje temporal - un momento del pasado-, las obras y los autores dignos de atención, los clásicos, para las instituciones educativas, los intelectuales y la crítica?, y

2) el marcado por Mignolo: el eje regional o diatópico ¿qué obras y autores son considerados universales para los intelectuales, instituciones y crítica de determinada sección espacial — país, región o comunidad cultural de cualquier tipo $^{\mathrm{IO}}$-?

9 En su artículo de Poetics Today (I99I, n.I2) «Canons $\mathrm{A}(\mathrm{nd})$ Cross-cultural Boundaries (Or, Whose Canon are we Talking About?)».

to Es de notar que cuando se habla aquí de espacio o de regiones no nos estamos refiriendo a espacio físico

A partir de ellos podría dibujarse el entramado de relaciones, influencias y tensiones de poder que el efecto del concepto de Literatura Universal sobre el eje diatópico y el estatus de 'clásico' sobre el eje diacrónico se han encargado de borrar.

Lejos de las teorías conservadoras, exclusivamente estéticas o universalistas dados sus presupuestos trascendentes, pero a favor de la conservación y cultivo del canon, se encuentra Frank Kermode, a quien Pozuelo llama por estas razones «conservador pragmatista», que da peso específico a la crítica y la actividad interpretativa de la literatura - y en concreto, al comentario- como responsable de la conservación del canon literario; por esta razón le asigna a las reescrituras y a las instituciones un papel decisivo, validador de «hábitos y consensos». Es el hecho de «seguir hablando» de ciertos textos lo que hace de ellos textos canónicos.

Kermode explicita también otra serie de criterios de selección de grandes obras: (I) proporcionan modelos, ideas... transmiten cierta herencia cultural, (2) responden a un esfuerzo de sistematización y de este modo ofrecen perspectiva histórica y un marco referencial común y (3) criterios menos confesables (intercambio de favores, pago de deudas, legitimación de teorías...) ${ }^{\mathrm{II}}$.

Aunque prevalece cierto ahistoricismo en su afirmación de que la permanencia de los textos como objeto del discurso sobre la literatura ha de deberse a características inherentes al texto capaces de evitar el agotamiento de su capa-

real, sino más bien a esos sistemas literarios más o menos interrelacionados pero con reglas propias de funcionamiento y una serie de agentes que los regulan —incluidas las literaturas construidas a partir de las revisiones críticas del canon-, ya sean las literaturas nacionales, literatura negra, literatura gay, literatura indigenista, literatura femenina, etc.

II Kermode, Formas de atención (I988: 63-64, en Pozuelo I995: I3). 
cidad de generar lecturas nuevas ${ }^{12}$, su teoría se presenta como una de las más interesantes y útiles de cuantas voces han surgido en torno al debate sobre el canon.

Esta tentación se compensa y se entiende gracias a su pragmática visión del canon como estrategia y por la importancia que otorga al adiestramiento de los hábitos interpretativos de los lectores y la necesaria función de la institución docente en ello, de la cual depende en gran medida la constitución y conservación del canon $^{\text {r3 }}$. Como veremos, el papel fundamental de la formación e instrucción académica, cuando se trata el tema del canon desde perspectivas sistémicas o críticas, es una constante que volverá a tratarse en estas páginas.

\section{I La teoría del campo de Pierre Bourdieu}

Este polémico sociólogo francés, que centró su labor en combatir el determinismo mecanicista instalado en los estudios sociológicos (Robbins 2000: 29) y cuyos planteamientos en materia de cultura han dejado huella en diversas disciplinas humanísticas, expone en su ensayo Las reglas del arte. Génesis y estructura del campo literario (1995) ${ }^{\mathrm{I4}}$ su propia teoría acerca de la formación y el fun-

I2 Quizá aquí también se trate de una inversión o 'borrado de huellas' (Bourdieu), que produce 'creencias' donde hay causas históricas claras. ¿Sería o no posible generar nuevas lecturas de textos sin un correcto adiestramiento de los lectores y los profesionales por parte de la institución competente? ¿Quién podría reinterpretar los textos si no hubiera sido previamente preparado para ello?

r3 Las relaciones de dependencia entre texto y metatexto y la importancia modeladora de éste está también en los cimientos de otras teorías, como la de I. Lotman. Encontramos una buena cantidad de coincidencias entre éstas y Kermode, por lo que sería interesante analizar si se dan influencias y relaciones entre ellas.

I4 Obra del mismo año que el artículo de Pozuelo con que se empieza este capítulo. Su contemporaneidad explica que Pozuelo no haga mención a él en su panorámica sobre el canon. cionamiento de lo que llamamos 'Literatura', donde el tema del canon y la perspectiva histórica son centrales. Convencido de que en el origen de tanto trascendentalismo en los metatextos literarios — si bien su teoría es aplicable también a cualquier otro tipo de bienes culturales- está «la amnesia de la génesis», después del diagnóstico, propone un tratamiento a la «enfermedad» digno de ser asumido como objetivo práctico: ${ }^{15}$

En contra de la amnesia de la génesis, que es lo que origina todas las formas de ilusión trascendental, no hay antídoto más eficaz que la reconstrucción de la historia olvidada y oprimida que se perpetúa en esas formas de pensamiento aparentemente antihistóricas que estructuran nuestra percepción del mundo y de nosotros mismos (Bourdieu 2002: 49I).

En Bourdieu, algo fundamental en la tarea de comprender el funcionamiento del campo literario es, pues, llegar a reconstruir las condiciones de posibilidad de la experiencia estética, es decir, desentrañar cuáles son las circunstancias que proporcionan valor a un corpus de textos en determinado momento histórico. El espacio donde se crean estas circunstancias favorables para la 'creencia' del valor, es lo que Bourdieu denomina 'campo literario' (Robbins 2000: 37-40).

Bourdieu resulta especialmente interesante, entre otros motivos, porque plantea una concepción ecléctica del campo literario: éste no es completamente autónomo como plantean los llamados conservadores universalistas (Pozuelo), pero sí relativamente; por otro lado, es también parcialmente dependiente del campo económico y del político (Bourdieu 2002:213). En su interior se da la oposición entre dos tipos

I5 En este método de reconstrucción histórica del discurso, la propuesta de Bourdieu nos recuerda al método genealógico nietzscheano y a la arqueología del saber de Foucault. 
de best-seller, el que no tiene futuro y el de larga duración, también denominado 'clásico' (Bourdieu 2002:223), cada uno de ellos forma parte de 194 una lógica económica distinta y un ciclo de producción diferente, de modo que sufren también formas distintas de envejecimiento.

En el caso de los best-sellers sin futuro, el valor es otorgado exclusivamente por el éxito comercial — que se espera que sea inmediato-, el ciclo de producción es, por tanto, corto - para minimizar riesgos económicos- y parte de un ajuste anticipado a la demanda, de modo que sus formas son preestablecidas por una clientela preexistente.

En cambio, los clásicos son frecuentemente canonizados postmortem a través de las instituciones educativas y sólo resultan accesibles a los consumidores competentes previamente 'producidos' — convenientemente instruidos - por la misma institución ${ }^{16}$. La lógica funciona a la inversa en este caso, lo sospechoso es lo económicamente rentable, fenómeno que genera una «represión constante y colectiva del interés 'propiamente' económico», fenómeno que Bourdieu llama «angelicalismo económico» (Bourdieu 2002: 225). Su ciclo de producción es largo y entraña riesgos, porque no tiene mercado en el presente, sino que se produce volcado al futuro. Es la lógica de la producción restringida, identificada con las vanguardias, con el «arte por el arte», y orientada a la acumulación de otro capital, el 'capital cultural' (Robbins 2000: 32-37). Pero para que esto se produzca son necesarias ciertas condiciones de privilegio que unen al autor de minorías con los pocos entendidos y aficionados a sus obras, la 'illusio' (Bourdieu 2002: 253), el juego cuyas reglas garantizan una posterior consagración en los altares académicos.

I6 La coincidencia con Kermode y su teoría de la instrucción del lector competente es clara.

\subsection{El reto de describir lo extrasistémico (Iuri Lotman)}

De la perspectiva sistémica lotmaniana, Pozuelo Yvancos ha extraído en su artículo tres aportaciones esenciales que, en su opinión, «la dramática incomunicación que vive la teoría literaria, producida y consumida a menudo en espacios teóricos reducidos, y la tendencia a la rápida sustitución de una teoría por su contraria» (Pozuelo 1995:28), han marginado: (I) el funcionamiento dinámico, (2) la conciencia metateórica y (3) la antinomia previsibilidad / imprevisibilidad.

Aunque la teoría lotmaniana no está -en los textos sobre los que trabaja Pozuelo- formulada específica y restrictivamente para el campo del canon literario, sino que es aplicable a cualquier sistema semiótico, Pozuelo insiste acertadamente en el interés de establecer una homología y hacer uso de las herramientas que ofrece frente al problema del canon literario.

De ella podemos extraer la siguiente definición de canon ${ }^{17}$ :

elenco de textos por los cuales una cultura se autopropone como espacio interno, con un orden limitado y delimitado frente al externo, del que sin duda precisa (Pozuelo 1995:30) ${ }^{18}$.

I) De este modo, la dinámica dialéctica entre estratos canonizados frente a no canonizados propuesa por Tynianov y Sklovski es sustituida por un funcionamiento dinámico en que centro - núcleo interno, con su orden, jerarquía y sometimiento a reglas - y periferia — externo y desorganizado-,

${ }^{17}$ Esta definición no es válida sólo para los 'cánones literarios', sino también para cualquier otro tipo de canon, histórico y positivo, convencional y comúnmente aceptado, de textos culturales, entendiendo 'texto' en términos de Semiótica de la Cultura, es decir como realización del mecanismo generativo y estructurador de textos de todo tipo que es la cultura.

I8 El subrayado es mío. 
construidos por el propio sistema semiótico, se definen y necesitan mutuamente.

Estos textos internos al corpus canónico tienen, además, una cualidad específica: su longevidad en una cultura dada, que se presenta como prueba de su validez o canonicidad, determinada ésta, en cambio, por valores autónomos e intrínsecos a los textos, como ya vimos. Sin embargo, dando cuenta de lo cierto de la longevidad de dichos textos, Pozuelo recurre a la dialéctica memoria / olvido de Lotman y Uspenski ${ }^{19}$ — según la cual la unidad de una cultura está determinada por el mantenimiento de la memoria unida a la posibilidad de cambio- para considerar el hecho empírico de su permanencia como algo que la cultura produce por necesidad unida a convenciones ideológicas y de valor, es decir, por lo útil que le resulta para elaborar su autodescripción y la construcción de su propia historia.

De este modo, además, se producen dos fenómenos: que, estimulado el centro del sistema por las instituciones, el canon que éstas difunden tiende a ser conservador y a regirse por categorías pertenecientes a estructuras anteriores a la presente y que las categorías vigentes en el presente se imponen - anacrónicamente- cuando se tratan momentos históricos anteriores.

2) Por otro lado, esta unidad que es necesaria a la cultura puede darse sólo a través de la fijación de fronteras que determinen su propia conciencia y organización, algo que se hace a través de 'metatextos', de los que son dependientes los textos culturales, pues sin conciencia de tal modelo autodescriptivo no podrían estructurarse y organizarse.

I9 Cfr. artículo «Sobre el mecanismo semiótico de la cultura» (I97I), en La semiosfera III. Semiótica de las artes $y$ de la cultura. (Lotman 2000:I68-I93), trad. del ruso por Desiderio Navarro.
Esto, aplicado al ámbito de la literatura, se traduce en la dependencia entre los textos pertenecientes al canon (obras, autores, modelos literarios canónicos) y ese metatexto (normas, reglas, teorías, crítica...) que organiza y estructura sus exclusiones y jerarquías internas, de tal modo que lo que denominamos Literatura deja de ser un grupo de textos independiente del mecanismo que los organiza (Pozuelo r995:32-35).

3) Este mecanismo hace de los textos pertenecientes al canon algo previsible, es decir, que, funcionando en un 'eje pasado-futuro' - en palabras de Pozuelo-, no producen innovación, sino mantenimiento, conservación y memoria de la descripción e historia de una cultura dada. Pero, ¿qué ocurre ante la introducción de elementos del 'eje presente-futuro', imprevisibles (textos creativos, innovadores, objetos de arte), que se manifiestan 'intraducibles' al código ya existente?

Cabe la posibilidad de que sean ignorados, de que se finja su inexistencia y se neutralicen sus efectos - como dice el mismo Lotman en un artículo al que luego nos referiremos ${ }^{20}$ pero, si son tenidos en cuenta, producen una explosión del código y necesitan de un nuevo código y unas normas propias que los regulen para poder integrarse en el sistema y ser interpretados. Es entonces cuando pasan al 'eje pasado-presente', con la renovación del canon, que no es sino una «lectura del presente hacia el pasado» (Pozuelo i995:36).

${ }^{20} \mathrm{Y}$ del que, no sé por qué motivo, Pozuelo no hace mención ni recoge información alguna a pesar de ser -en mi opinión - una mina para el tema que aquí se trata. Es «Un modelo dinámico del sistema semiótico», que, sin embargo, ha dejado clara huella —o al menos eso se deduce de la lectura de ambos- en las recientes revisiones de la teoría polisistémica, de las que se hablará a propósito de canon y traducción (capítulo I.3 del presente trabajo). 
Así,

196
Todo canon se resuelve como estructura histórica que lo convierte en cambiante, movedizo y sujeto a los principios reguladores de la actividad cognoscitiva y del sujeto ideológico, individual o colectivo, que lo postula

(Pozuelo 1995:38).

Sin embargo, Pozuelo Yvancos no trata en su estudio sobre el canon un conocido artículo de Iuri Lotman, «Un modelo dinámico del sistema semiótico» (I974), que aborda éstas y otras cuestiones aportando principios, conceptos y herramientas teóricas muy interesantes para afrontar desde un punto de vista más consecuente con los movimientos históricos y más flexible todo lo referente al canon y su dialéctica con la censura ${ }^{21}$.

En él, tras recordar el acierto de Jakobson al combinar las propiedades de homeostaticidad y dinamismo imprescindibles para la revisión de cualquier teoría, el autor constata un error de toda metodología descriptiva: su estaticidad. Ésta - dice- debe ser corregida, pues ni el estudio sincrónico de un objeto debería imponerla (Lotman I974:63-64) ${ }^{22}$.

$\mathrm{El}$ artículo se divide en cinco secciones en las que trata otras tantas antinomias: (I) sistémico / extrasistémico, (2) unívoco / ambivalente, (3) núcleo / periferia, (4) descrito / no descrito y (5) necesario / superfluo. Dado que las referencias son, como decíamos arriba, a cualquier sistema

21 Hay que decir, sin embargo, que su amplio conocimiento de los textos lotmanianos le ha permitido extraer de ellos una serie de consecuencias para el discurso sobre el canon que tienen mucho que ver con el artículo que glosamos en estas páginas.

${ }_{22}$ Por comodidad a la hora de identificar cronológicamente el artículo y sus relaciones con otros, en los paréntesis se da la fecha de la primera publicación, aunque la numeración de páginas corresponde a la edición compilada de éstos reseñada en la bibliografía. semiótico y a la cultura en general, se expondrán aplicados a su vez al caso de las literaturas, de los cánones literarios y de la censura, que es lo que nos interesa.

I) Lo sistémico - para nosotros, lo literario o lo canónico- es definido como «elementos invariantes en caso de transformación homomorfa del objeto» (Lotman I974:65) y es presentado como «única realidad», mientras que los elementos extrasistémicos, - no canónicos - inestables e irregulares, son eliminados de la descripción. Éste es un procedimiento que simplifica el objeto de estudio, y que por tanto utiliza mucho la ciencia, ya que le permite una descripción que de otro modo sería inabarcable, aún a expensas de que el objeto no esté realmente tan organizado como su descripción. Pero esto, que es válido para objetos estáticos, no lo es para los objetos dinámicos.

Los sistemas dinámicos entrañan la dificultad del arrastre de elementos extrasistémicos a la órbita de la sistemicidad y la expulsión de lo sistémico al dominio de la extrasistemicidad. Es el juego entre la evolución y la homeostasis, en que la piedra desechada por el sistema resulta ser la piedra angular del que le sucede. Por ello - sugiere Lotman- es tan necesario describir lo extrasistémico, lo no canónico, poner nombre a los textos que se escapan de la nomenclatura, a pesar de la dificultad de que, al hacerlo, podamos escapar del pensamiento analítico, al menos en los términos en que el sistema - $\mathrm{O}$ canon- está descrito previamente y que su descripción implique su absorción por parte del sistema (Lotman i997:66-68).

Resulta necesario entonces evitar deslizarse en la concepción de lo 'extrasistémico' como 'caótico' y optar por percibirlo como elemento complementario del sistema que puede a su vez conformar un sistema paralelo (alosistémico) con sus propios elementos, jerarquías y rela- 
ciones aunque - como ocurre en la dialéctica canon/censura, en que la imposición ideológica elude la descripción de una serie de textos, eliminando así su existencia- el sistema para el que resulta extrasistémico lo haya obviado.

Se exige entonces un metalenguaje analítico diferente del aparato autodescriptivo ya elaborado, puesto que es él mismo quien crea el objeto sincrónica y diacrónicamente - construye para su objeto (la literatura) una historia propia entendiendo ésta como el paso de cierto estado amorfo a uno estructurado, y no un relevo de estados estructurales-, no permitiendo así dar cabida al estudio de un objeto que le es ajeno. En otras palabras: no es posible analizar lo que quedó fuera del canon clasicista si utilizamos el metalenguaje analítico que para él fue creado, por tanto son necesarios otros parámetros, principios y categorías diferentes.

De ello se extrae que, para el estudio de una cultura, literatura, canon... en una etapa histórica dada, es necesario tener en cuenta tanto (I) la descripción de su estructura desde la posición del historiador como (2) la traducción al lenguaje de la descripción que ésta se dio a sí misma y de la descripción del desarrollo histórico por ella creada (Lotman r974: 72).

2) Por otro lado, — dice Lotman - aunque la relación binaria es un mecanismo organizador fundamental de toda estructura, entre ambos polos se sitúa una franja de neutralización estructural donde se dan relaciones ambivalentes, que aporta flexibilidad e imprevisibilidad al sistema. Lo cual, aplicado al canon, sirve para tratar aquellos textos que no se sitúan en lo canónico ni en lo censurado y, en el ámbito de la traducción puede ser aplicado al papel de la interpretación en el proceso traductor, que activa unas $\mathrm{u}$ otras valencias de sentido en un «texto que se puede pensar bien de varias mane- ras» (Lotman 1974: 73), es decir, en textos con un cierto grado de ambigüedad y apertura a la interpretación como los textos literarios.

A nivel sistémico, la mayor ambivalencia refleja un estado dinámico del sistema donde una redistribución de la indefinición dará un nuevo sentido unívoco; simétricamente, una mayor univocidad interna está relacionada con tendencias homeostáticas más intensas, es decir, cierto anquilosamiento.

En tales estados dinámicos del sistema se producen casos de: (I) relación entre un texto y un sistema no vigente pero presente en la memoria de la cultura —-donde se guarda todo un repertorio de metasistemas-, lo que produce una violación de la norma, como - por ejemplo- la composición de textos dramáticos en verso en el sistema literario español contemporáneo; (2) relación entre un texto y dos sistemas no ligados entre sí y, por tanto, con posiciones diferentes dentro de cada uno de ellos. Un ejemplo de nuestro interés para ello pueden ser las películas censuradas en el sistema cultural español durante el periodo franquista que, sin embargo, eran proyectadas en Francia y que algunos españoles se desplazaban para ver (autorizado vs. prohibido).

Gracias al repertorio de metasistemas presente en la memoria de la cultura cualquier texto ambivalente puede pasar de la incorrección (extrasistematicidad, inexistencia, censura) a la corrección (sistematicidad, existencia, canon) y viceversa. Este desplazamiento en etaniveles que cambia la interpretación del texto y este cambio de lugar del texto respecto a los metasistemas es un mecanismo que garantiza la dinámica del sistema (Lotman I974:72-76).

3) La aplicación a nuestra disciplina de la afirmación de Lotman según la cual la descripción de la estructura es diferente para elementos 
internos y externos a ella se puede ilustrar de la siguiente forma: el canon y la historia de la literatura italiana, por ejemplo, están estruc198 turados diversamente para un agente externo - por ejemplo, un estudiante, crítico, lector, traductor... español- y para uno interno - un estudiante, crítico, lector, traductor... italiano- y las historiografías literarias presentan estructuras diferenciadas aunque aparentemente los referentes sean los mismos.

La negación de la periferia que se da en la descripción de cualquier lenguaje social —en este caso, el del canon literario-y que hace a ésta inexistente produce, inevitablemente, una deformación. La consideración de la periferia en la observación de esos procesos dinámicos - la formación del canon de las literaturas nacionales, el paso de un estado poético a otro, de un sistema literario lábil a otro más estable, la aceptación de textos o modelos antes ignorados y viceversa - es imprescindible, ya que éstos no son sino deslizamientos que se producen entre ella, que es flexible, y el núcleo del sistema, caracterizado por su rigidez.

4) La necesidad de metadescripciones que estabilicen el sistema - mecanismo fundamental de la evolución semiótica- exige que, en caso de trabajar para lenguajes con función social secundaria ${ }^{23}$, se busquen equivalencias en las intersecciones de lo común de ambos

${ }_{23}$ Es decir, que no pretenden la comunicación de un hecho desconocido del receptor para situarlo en paridad informacional respecto al emisor (en donde prima reducir las dificultades de comprensión y, por tanto, la necesidad de encontrar un código único) [Un ejemplo de ello puede ser la labor que realizan los intérpretes simultáneos en situaciones en que se exige una negociación con referentes extralingüísticos concretos: de compra - venta de bienes, toma de decisiones políticas o económicas...], sino que, siendo 'emisor' y 'receptor' repertorios de códigos, lo que se pretende es el enriquecimiento a partir del conocimiento de puntos de vista ajenos, de otras posiciones. códigos, aunque con ello «se pierda en la traducción». De ello se deriva un sistema modelizante secundario - la crítica, la teoría, la literatura comparada...- necesario para el diálogo entre códigos y que cumple una función doble simplificando el sistema y actualizando su unidad. Es ejemplo de ello en terreno lingüístico la imposición de lenguas de cultura - como argamasa de la cultura nacional- a comunidades que se comunicaban con diversos dialectos a lo largo de un territorio estatal, como en el caso de Italia.

5) La separación en la descripción entre lo necesario - lo que funciona-y los elementos y nexos superfluos - que producirían una ambigüedad no aceptable - produce la redundancia necesaria para aumentar las equivalencias e interconmutabilidades entre diferentes códigos.

6) Dada la función compleja que realiza, este modelo es más dinámico aún en el lenguaje poético, ya que - al no ejercer una función meramente comunicativa referencial, no puede funcionar en estado fosilizado, sino que necesita al entorno extrasistémico que le proporcione vínculos desautomatizados $\mathrm{y}$, con ellos, el mecanismo de renovación que anima la dinámica histórica que lo caracteriza. En la tensión que se produce entre estos polos ideales tienen lugar las complejas relaciones de interacción de la cultura (Lotman I974: 80).

Entendemos, pues, que parte esencial — con su dosis de reto y de peligro- de la labor propia de la Semiótica de la Cultura, los Estudios Descriptivos de Traducción y la Literatura Comparada es la formulación de este metalenguaje que hace posible el diálogo entre elementos sistémicos y extrasistémicos, entre sistemas diferentes y códigos distintos legitimando y facilitando, con ello, el dinamismo del sistema. 


\section{LA TRADUCCIÓN COMO ACTIVIDAD MODELADORA DEL CANON}

Like all activities to do with re-writing, translation is never innocent

(Hatim 2001: 62)

\section{I La manipulación del canon (André Lefevere)}

El mismo año (I992) en que se publicó el trabajo de Bourdieu del que hablábamos, Las reglas del arte, André Lefevere publicaba Traducción, reescritura y manipulación del canon literario, donde se tratan numerosos aspectos similares, pero desde la perspectiva de los estudios de traducción ${ }^{24}$.

La escuela de la manipulación -enfoque «descriptivo y sistémico» llamado también «nuevo paradigma» y cuyas bases estableció Hermans en su introducción a The Manipulation of Literature (I985) (Hurtado 2001: 558-560) - entiende la literatura y, con ella, la traducción literaria, como un sistema complejo y dinámico cuyas normas de producción y recepción necesitan ser extraídas a partir de un método descriptivo, funcional y sistémico orientado al texto meta que haga posible una constante comunicación bidireccional entre modelos teóricos y casos prácticos (Hurtado 200I:56I) ${ }^{25}$.

Como reacción a la excesiva restricción y formalismo a los que tendían los análisis produci-

24 Es de rigor apuntar aquí que en su volumen precedente con Susan Bassnett, Translation, History and Culture, del año I990, ya se introducen algunos de los conceptos que más tarde desarrollará Lefevere en el libro del que nos ocupamos.

${ }_{25}$ Otra tendencia dentro de este mismo enfoque es la del grupo de Tel-Aviv, al que pertenecen Toury y EvenZohar, responsable de la formulación de la teoría de los polisistemas, de los que hablaremos más adelante. dos hasta entonces desde el «nuevo paradigma», el grupo holandés «adopta un modelo más cultural, interdisciplinario, centrándose en el papel de las instituciones y del poder dentro de una

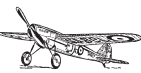
cultura» ${ }^{26}$, para lo que adapta el pensamiento foucaultiano (Carbonell I999: I95, en Hurtado 200I: 566).

Esta perspectiva híbrida entre los estudios culturales y los de traducción es resumida por Hatim en un corolario central, "Like all activities to do with re-writing, translation is never innocent» y una serie de factores fundamentales a tener en cuenta:

(I) el contexto en que se da la traducción,

(2) la historia de la cultura fuente y de la cultura de destino y

(3) el lugar que el texto había ocupado en un sistema literario determinado frente al que ocupa después de ser traducido (Hatim 200I: 62).

El último de estos factores ilustraría de forma esquemática el núcleo central de interés del presente trabajo, pues cuando se habla de canon y censura, en términos sistémicos, -sin por ello dejar de tener en cuenta la función capital de historia y contexto- hablamos fundamentalmente de posiciones centrales o periféricas dentro de él.

Aunque Lefevere aúna una serie amplísima y heterogénea de textos bajo la denominación de 'reescritura', textos producidos por diferentes agentes a partir de un texto original que - en el proceso de reescritura- resulta adaptado, manipulado - traducciones, historias literarias $^{27}$, versiones reducidas, obras de consulta,

26 Genzler 1993: 139, en Hurtado 200I: 566.

27 La historiografía tiende a eliminar los rasgos y figuras que no responden a la imagen canonizada de su cultura. Su supervivencia la garantizan las reescrituras (Lefevere I997: I4I). 
antologías $^{28}$, críticas $^{29}$ o ediciones (Lefevere I997: 2I), adaptaciones para cine o televisión (Lefevere I997: 22)—, se extiende más en el
[...] la traducción es la reescritura más obviamente reconocible y [...] potencialmente la más influyente porque es capaz de proyectar la imagen de un autor y/o una (serie de) obra(s) a otra cultura, elevando a ese autor y/o esas obras más allá de los límites de la cultura de origen [...] (Lefevere 1997: 22).

Lefevere trata, a lo largo de todo su libro el tema central del canon dentro del sistema literario, para lo cual observa, dentro del sistema, dos factores de control que actúan sobre los agentes de la cultura (lectores, escritores, reescritores...) y los mantienen dentro de sus límites garantizando el orden y la relación con otros subsistemas sociales:

I. el factor profesional, interno: críticos, escritores de reseñas, profesores y traductores, clase que define el prestigio y la aceptación de ciertos textos conforme a unos intereses ideo-

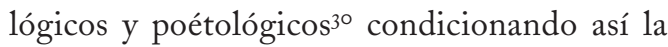
producción posterior, $\mathrm{y}$

2. el factor de mecenazgo, externo al siste-

${ }_{28}$ La antología permite un cierto grado de canonización temprana y aceptación de un canon emergente a través del proceso de subversión/ampliación (Lefevere I997: I53-I68).

29 Gran responsable de la imagen que se proyecta de un escritor, un texto o un fenómeno cultural. El autor lo ilustra con el caso de Madame de Staël, cuya imagen está sembrada de estrategias de disculpa, apología y memoria selectiva por parte de los críticos. Ya sea por su educación, por su condición de mujer o por su carácter, la obra de la autora ha quedado dibujada a la sombra de numerosas interpretaciones que toman su biografía como indicio principal (Lefevere I997: r69-I8I).

30 Los capítulos 5 y 6 ilustran esto a través del análisis de (I) las transformaciones que sufrió el texto original del Diario de Anne Frank por motivos fundamentalmente ideológicos ligados al momento político, las sensibilidades nacionales de posguerra y la moral sexual del momento y (2) la recepción, crítica y antologización de los géneros ma literario: los poderes -en sentido foucaultiano-, personas e instituciones: academias, censura, revistas especializadas e instituciones educativas) que actúan por motivos fundamentalmente ideológicos y cuya aceptación implica y obliga a la capacidad de autolegitimación de parte de sus diversos agentes (Lefevere 1997: 33)

El factor de mecenazgo de Lefevere está formado por tres elementos:

(I) el componente ideológico — sentido de Jameson, «entrelazado de forma, convención y creencias que ordena nuestras acciones» (Lefevere 1997: 30)—,

(2) el componente económico, que proporcionas subvenciones o puestos de trabajo a los escritores, $y$

(3) el estatus, que determina la integración en un determinado grupo (Lefevere 1997: 30-3I).

Si intentáramos recuperar en este punto las dependencias que Bourdieu atribuía al campo artístico, podríamos a simple vista reconocer ciertos paralelismos: (I) lo que Bourdieu llama 'dependencia del campo político' puede identificarse con el componente ideológico de Lefevere; y (2) lo que para Lefevere es el componente económico del factor de mecenazgo puede hacerse corresponder con la dependencia del campo económico a la que hace referencia Bourdieu. Podríamos, además, asociar el tercer

líricos (pre-) islámicos , para cuya introducción se utilizaron discursos de apología/admiración o analogía en un principio y, posteriormente, enfoques relativistas, pero que no han conseguido 'llegar' al público euroamericano (poética occidental) por diferencias en dos campos: la labor traductora incapaz de recoger el mayor valor de estos textos (la imagen) y las diferencias entre los Universos del Discurso (los lectores occidentales carecen de la capacidad de rellenar vacíos implícitos con la imaginación, como se presume del público receptor del texto original. (Lefevere I997: 79-IIO). 
componente de Lefevere, el 'estatus', a la que Bourdieu denomina 'distinción' ${ }^{3}$.

La parte del campo literario que Bourdieu reserva a esa relativa autonomía puede ser asimilada a lo que Lefevere llama 'poética', formada por dos componentes: (I) «un inventario de recursos literarios, géneros, motivos, situaciones y personajes prototípicos y símbolos» y (2) «una idea de cuál es, o debería ser, el papel de la literatura en el sistema social» (Lefevere 1997: 4I).

Su codificación se produce en un momento determinado - es decir, es ineludiblemente una variable histórica ${ }^{32}-$ con posterioridad a la puesta en práctica de los procedimientos que quedarán fijados con ella, e implica la aceptación de ciertos elementos y exclusión de otros ${ }^{33}$. Esta codificación, conformadora de sistemas, ejerce una enorme influencia sobre el desarrollo de éstos y viene condicionada, principalmente, por fuerzas ajenas a aquél, de modo que en ella juegan un importante papel las reescrituras proyectando imágenes e introduciendo recursos de inventario que facilitan el cambio.

Aunque - a nivel teórico-, teniendo en cuenta que el componente ideológico del factor de mecenazgo de Lefevere tiene un radio de acción mucho más amplio que el campo político de Bourdieu, pudiera parecer erróneo aceptar la identificación entre 'ideología' y 'política', parece ser que - a nivel práctico- a la hora de aplicar estos conceptos al análisis de casos concretos, los elementos de estudio en

${ }^{3 \mathrm{~T}}$ Para un amplio tratamiento de este mecanismo de actualización de las categorías sociales, véase Bourdieu (1979) La distinction. Critique sociale du jugement.

${ }_{32}$ Sin embargo, suele presentarse como ahistórica autoimponiéndose en términos absolutos con tres finalidades fundamentales: (I) eliminar a sus predecesoras, (2) negar su propia transitoriedad y (3) verse como fase final de un proceso de desarrollo. (Lefevere i997: 5I)

33 Esta codificación de la poética no puede desligarse del resto de los factores de canonización que formaban parte de los factores de control arriba descritos. cuestión serían los mismos: las «instituciones de registro, de conservación y de análisis de las obras» (Bourdieu 2002:258) ${ }^{34}$, los agentes que se ocupan de la creación del valor, de generar la condiciones que garanticen la producción y reproducción de ciertos habitus 35 (Robbins 2000: 26-29) —estrategias, comentarios (Kermode), formas de lectura, actos de validación (Smith)...- necesarios para perpetuar el valor de determinadas obras y su lectura canónica (Bourdieu 2002: 259-26I). Encontramos un gran consenso, pues, en que estos mecanismos son responsables directos - aunque no exclusivos- de la canonización.

Además, en caso de existencia de elementos insubordinados, es decir, que serían bloqueados por los factores de control del sistema, se da con frecuencia que tales elementos influyen indirectamente en él a través de su publicación en el exterior (Lefevere 1997:37) para, a través de ella, alcanzar aceptación, absorción o neutralización por parte de la corriente dominante e, incluso, imitación desde el interior de ésta, permitiendo así la renovación y, con ello, garantizando la funcionalidad del sistema. Ejemplo de ello es la potencia editorial de Amsterdam y Estrasburgo para el sistema literario francés del xviıI o la publicación de textos españoles en editoriales americanas durante el Franquismo.

Lefevere establece, además, una tipología de mecenazgos:

34 Pensamos que el hecho por el que Bourdieu no utiliza el término 'ideología' en este contexto es porque tiende a identificarlo con la noción de la primera escuela de Frankfurt, como «sistema de ideas que legitiman un régimen de dominación», mientras la propuesta de Lefevere remite a una concepción más abierta, como de «procesos significantes prácticos que respaldan ciertas formas de poder o programación social» (Méndez Rubio 1997: 7I).

35 (Bourdieu, 1979: 545), también citado por EvenZohar 1997 a propósito del vínculo entre el repertorio y su interiorización individual (Even-Zohar 1997:38) 
I. indiferenciado, cuando se da que sus tres componentes son administrados por un mismo mecenas, algo característico de los estados totalitarios, $\mathrm{y}$

2. diferenciado, en que el éxito económico es relativamente independiente de los otros dos, como en el caso de los best-sellers contemporáneos.

En el mecenazgo indiferenciado es donde tradicionalmente se insertan los mecanismos de censura, que son claramente visibles en los estados totalitarios, pero que existen de forma soterrada en otros tipos de estado, como se verá en las conclusiones del presente trabajo bajo el título «formas de censura».

Contra la búsqueda de estabilidad del sistema y a favor de su dinamismo actúan dos principios,

(I) el de polaridad, según el cual «cada uno acaba por desarrollar su propio contrasistema» , y

(2) el «de periodicidad, que afirma que todo sistema está sujeto al cambio» (Lefevere I997:54),

El mecenazgo asume el papel regulador de la tensión - latente o patente- entre éstos y el intento del sistema de alcanzar estabilidad (recuérdese Lotman). Además, a propósito particularmente del dominio de la traducción literaria, Lefevere afirma que la imagen de una obra literaria y su proyección mediante una traducción está determinada por dos factores: (I) la ideología del traductor (voluntaria o impuesta), y (2) la poética dominante en la literatura receptora en el momento en que se produce la traducción. Ambas deciden la estrategia de traducción cuando se plantean problemas relacionados con el Universo del Discurso.

\subsection{La teoría de los polisistemas (Itamar Even- Zohar)}

Hermans, el mismo estudioso que formuló, en 1985 , los principios básicos de este nuevo paradigma - el de la manipulación- en Traductología, hace en I999, en su libro Translation in Systems, unas durísimas - aunque muy pertinentes - críticas a las limitaciones de la teoría polisistémica (Hurtado 200I: 567). Sin embargo -desde una perspectiva ecléctica- ésta ofrece, como veremos a continuación, ciertos instrumentos valiosos para enmarcar no sólo el análisis de las relaciones entre traducción, canon y censura $^{36}$, sino también de numerosos fenómenos que se dan dentro de los sistemas culturales y en las relaciones entre sistemas diferentes ${ }^{37}$.

Las limitaciones de que se le acusa son:

(I) la falta de atención a las relaciones de poder, políticas, instituciones y grupos que imponen o ejercen influencia a partir de determinados intereses,

(2) la carencia de investigación acerca de las causas que producen ciertas correlaciones entre normas, cambios de género y otros fenómenos observables en la traducción literaria,

(3) el reduccionismo de un modelo excesivamente estructurado y basado en oposiciones binarias que dejan fuera tantos elementos que se resisten a esta clasificación.

Creo que la aplicación de una noción de sistema más flexible y dinámico, de corte lotmaniano - algo que ya hace el mismo EvenZohar en recientes replanteamientos de su teoría (Even-Zohar I997:27)—, y la adopción

${ }^{6}$ A esto hay que añadir que, ya antes de la publicación de la crítica de Hermans, el propio Even-Zohar había revisado su teoría en "Factores y dependencias en la cultura. Una revisión de la teoría de los polisistemas», como veremos en las páginas siguientes.

37 Al final de la primera parte y en la segunda parte de este trabajo pueden verse dos aplicaciones de ella. 
de la perspectiva - integradora del poder y la cultura - que propugnan Bourdieu o Lefevere, pueden favorecer una superación de estas limitaciones.

Algo similar a esto, es decir, el diálogo con otros planteamientos sistémicos como los de Lotman o Bourdieu, parece - de todos modos- estar en la agenda actual de los estudios basados en el polisistema ${ }^{38}$.

Entendiendo el 'polisistema' como:

conjunto de co-sistemas semióticos interrelacionados de forma dinámica y regulados por formas históricas, en el que se inscriben todas las actividades behaviorísticas y sociales del ser humano, incluida la propia traducción (Rabadán 1991: 294 en Hurtado 200I: 562)

y concibiendo la literatura como un sistema dinámico, heterogéneo y complejo, en «Factores y dependencias en la cultura. Una revisión de la teoría de los polisistemas», artículo aparecido en marzo de 1997, Even-Zohar expone la necesidad de tener en cuenta otros factores culturales.

Antes de exponer el planteamiento que en estas recientes apostillas se hace de la cuestión del canon, es necesario exponer en que consisten éstas:

La base lógica de esta teoría está en el 'pensamiento relacional', que permite afrontar una amplia y compleja serie de fenómenos a partir de un número relativamente pequeño de relaciones y cuyos elementos fundamentales se integran en una adaptación del célebre esquema Jakobson-Bühler de la comunicación y las funciones del lenguaje:

En una aplicación de este esquema al fenómeno literario -original o traducido- el 'repertorio' sería el conjunto de reglas y mate-

$3^{8}$ Iglesias Santos, M. (I999) «La teoría de los polisistemas como desafío a los estudios literarios» en Teoría de los polisistemas (1999), Madrid, Arcolibros.

\begin{tabular}{ccc}
\hline & $\begin{array}{c}\text { INSTITUCIÓN } \\
\text { (contexto) }\end{array}$ \\
\hline & $\begin{array}{c}\text { repertorio } \\
\text { (código) }\end{array}$ \\
\hline $\begin{array}{c}\text { PRODUCTOR } \\
\text { (emisor) }\end{array}$ & $\begin{array}{c}\text { PRODUCTO } \\
\text { (mensaje) }\end{array}$ & $\begin{array}{c}\text { CONSUMIDOR } \\
\text { (receptor) }\end{array}$ \\
\hline & $\begin{array}{c}\text { MERCADo } \\
\text { (canal) }\end{array}$ \\
\hline
\end{tabular}

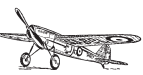

203

riales que regulan la producción (uso activo) y el consumo (uso pasivo) de los textos —originales o traducidos - y que debe ser legitimado por la 'institución' (crítica, universidad, editoriales, revistas... $\left.{ }^{39}\right)$. A partir de su potencial, surgen 'productos', es decir, textos ${ }^{40}$ que lo ponen en práctica y suponen una realización de éste.

El repertorio funciona en dos niveles diferentes y complementarios:

(I) el de las cadenas de 'elementos' o 'repertoremas' $\mathrm{y}$

(2) el de los 'modelos', combinación de elementos, reglas y relaciones sintagmáticas presentes en la experiencia colectiva previa y no universales ${ }^{4 \mathrm{I}}$.

Así, el 'repertorio canonizado' estaría formado por aquellas obras o normas que los círculos dominantes de la cultura (la institución) aceptan como legítimas y cuyos productos más sobresalientes son preservados por la comunidad para que formen parte de la herencia histórica. (Even-Zohar I997: 49-50). La canonización

39 En algunos casos, como el del mundo editorial, la institución y mercado se solapan y resulta imposible deslindarlos.

40 En el sistema socio-semiótico, los escritores y otras personas cuya función sea derivada del repertorio y su legitimación por parte de la institución (críticos, censores, profesores, lectores...) pueden ser consideradas 'producto', son los llamados por Even-Zohar «agentes socio-semióticos» (Even-Zohar 1994: 369).

4I Puede relacionarse con el habitus de Bourdieu. 
de los textos puede, a su vez, producirse de dos formas distintas:

(I) como texto que entra en el repertorio 204 con el rango de producto - canonización estática-y

(2) como modelo que entra en el sistema a través del repertorio y puede, a su vez, generar canon - canonización dinámica-

Cuando se trata de estudios de traducción, nos puede resultar útil — más que las 'intrarrelaciones', que interesan a cualquier sistema semiótico (lingüístico, literario..)-

(I) las 'interrelaciones', que correlacionan los sistemas controlados por unas comunidades con los controlados por otras y

(2) las 'interferencias' que se dan entre unos y otros sistemas.

¿Qué textos de aquella comunidad se traducen en esta otra en determinado periodo de tiempo? ¿Cómo se traducen? ¿Traducción directa o de segunda mano? ¿Quién los traduce? ¿Son domesticados para facilitar su introducción a través de antologías ilustradas, glosas críticas o mecenas de reconocido prestigio en el sistema de llegada? ¿Qué posición ocupan en el sistema literario que los recibe? ¿Llegan a ser una influencia en él o se mantienen en la periferia? ¿Modifican o cuestionan el canon? ¿Cuándo es un sistema literario más permeable a la entrada de textos traducidos y cuándo lo es menos? ¿Por qué razones? ¿Se recuperan textos antiguos mediante la retraducción? ¿Se dan casos de textos ya presentes que, una vez retextualizados, cambian de posición en el campo literario? ¿A qué se debe esto? ¿Tienen una recepción diferente los textos canonizados en el sistema de origen? ¿En qué casos resultan canonizados también en el sistema de llegada?

Éstas son sólo algunas de las preguntas que esta revisión de la teoría polisistémica sugiere

responder. Quizás sus instrumentos de análisis, esa rejilla de elementos y relaciones, ayuden a observar y describir, entre otros fenómenos culturales, los procesos de canonización y censura.

\subsection{Los estudios descriptivos de traducción (Gideon Toury)}

Para analizar la formación de cánones y los mecanismos de censura - a través de las traducciones- de forma empírica y poder producir resultados teóricos que puedan a su vez ser aplicados a la práctica, es esencial adoptar una perspectiva de observación descriptiva de la mayor cantidad posible de elementos en juego.

En este sentido, la metodología propuesta por los EDT parece la más adecuada, ya que exige la consideración de los tres - llamados- «enfoques» en traducción: orientados a (I) la función, (2) el proceso y (3) el producto; evitando su estudio aislado respecto a la cultura de origen y/o la cultura meta. En Los estudios descriptivos de traducción y más allá. Metodología de la investigación en estudios de traducción, Toury lo pone de manifiesto de la siguiente forma:

considerar los tres campos [enfoques (I) orientado a la función, (2) al proceso y (3) al producto] como autónomos respecto a la posición de la traducción en la cultura en que surge o en la que se integrará; o al proceso mediante el que un texto traducido se deriva de un original; o a la configuración lingüistico-textual de una traducción [...] no se puede formular hipótesis explicativa ni remotamente satisfactoria a menos que los tres aspectos confluyan (Toury 2004: 47).

Más adelante, en la misma página, añade:

Se deberá aspirar a desvelar las interdependencias entre los tres aspectos, si queremos llegar a conocer las complejidades de los fenómenos relacionados con la traducción, y hacerlo dentro de una (inter)disciplina unificada. 
Tal como enuncia Toury, una de las finalidades principales de los EDT, trabajando empíricamente sobre textos que ya existen, debiera ser que sus resultados influyeran en la rama teórica de los estudios traductológicos, que trabaja en el terreno de la probabilidad ${ }^{42}$, permitiendo, a partir de una serie de regularidades de comportamiento en unos parámetros controlados, la enunciación de leyes coherentes que establezcan las relaciones y variantes del campo ${ }^{43}$ hacia una teoría general de la traducción.

Dado que las traducciones son hechos de la cultura meta con estatus propio y posición concreta - aunque en constante movilidad y negociación- en su subsistema, lo que exige su contextualización ${ }^{44}$. Partiendo sólo de lo que es observable 45 (Toury 2004: 78), se examinan los textos individualmente y se evalúa su aceptabilidad a todos los niveles, así como las relaciones unidireccionales y reversibles entre los textos emparejados —origen y traducción-. Estas relaciones - normas de equivalenciaextraídas deben vincularse con un concepto de traducción que podrá aplicarse posteriormente al estudio de un contexto más amplio. En cada una de estas fases se presume la formulación de hipótesis explicativas - progresión en espiral-.

42 Ésta es, obviamente, la Teoría de la Traducción propuesta por teóricos como Itamar Even-Zohar, para tomar las riendas de una Teoría básica de la Traducción cuyos criterios son exclusivamente teóricos y que trabaja en el indeterminado terreno de la mera posibilidad (Toury 2004: 57).

43 Éstas, como se verá más adelante, son leyes condicionales, es decir, formuladas a partir de una serie de factores condicionantes, jamás leyes absolutas (Toury 2004: 53 ).

44 Toury advierte de la importancia de no identificar completamente lengua y cultura, pues su relación unívoca es una salida fácil pero errónea (Toury 2004: 70).

45 No es necesario extenderse en la importancia del criterio de selección del corpus (traductor, escuela, periodo, tipo de texto, fenómenos lingüístico-textuales...) (Toury 2004: 80).
Toury parte además del hecho de que la posición de un texto «viene determinada ante todo por las consideraciones que surgen en la cultura que lo aloja» (Toury 2004: 66) y que «una traducción no podría compartir de ningún modo el mismo espacio sistémico que su original» (Toury 2004: 67) aunque, eso sí, se dan casos — privilegiados para el estudio - en que las traducciones ejercen influencia sobre los textos originales y los sistemas culturales que los alojan.

Recuerda Toury postulados de gran calado en los estudios sistémicos de traducción como (I) aquél según el cual la actividad traductora y sus productos provocan cambios en la cultura meta, (2) que los sistemas culturales recurren a la traducción en momentos de necesidad para rellenar sus vacíos ${ }^{46}$.

A la hora de analizar una traducción, subraya, nos interesa especialmente la posición que se pretendía que ocupara cuando salió por primera vez, pues es la que condicionó su gestación. Esto se extrae de «a) la posición original del texto respecto a los hallazgos relativos a su configuración y formulación, y b) el modo en que representa a su original» (incluido el peso de la tradición de traducciones).

Para definir las normas de traducción, Toury apela a sus limitaciones: (I) potencial.- restricciones socioculturales, escala limitada por dos extremos, la norma se sitúa entre dos factores intersubjetivos, las reglas generales absolutas y

${ }^{46}$ Esta carencia y su materia de relleno son consideradas entidades textuales y, en casos complejos, incluso modelos (Toury 2004: 68). Even-Zohar y José Lambert han extraído algunas normas de la observación en relación a esto.Véase el artículo de Even-Zohar «La posición de la literatura traducida en el polisistema literario» (Iglesias Santos I999: 223-23I), de Lambert «Aproximaciones sistémicas y literatura en las sociedades multilingües» (Iglesias Santos I999: 53-70), «Literatura, traducción y (des)colonización» (Iglesias Santos 1999: 257-280) y de Clem Robyns «Traducción e identidad discursiva» (Iglesias Santos I999: 28I-309). 
los rasgos idiosincrásicos; (2) eje temporal- en él toda restricción es susceptible de variación. La no adecuación a las normas de socialización 206 - traductores como ejecutores de un rol social en particular legitimado por una comunidad en concreto- implica excepcionalidad y - por tantosanción - llamémosla 'censura', en I.4 se explica por qué-, aunque no siempre invalida la norma (véase Hermans I991: I62), de hecho son con frecuencia estos comportamientos los responsables de los cambios que se producen en el sistema ${ }^{47}$.

Resulta estimulante preguntarse a quiénes y bajo qué circunstancias se permite introducir cambios, aunque la búsqueda de regularidades de comportamiento sea la base para la formulación y el estudio de normas, objetivo fundamental de los EDT.
Nos encontramos que, en definición de Gideon Toury, el objeto de nuestro estudio - las traducciones- son: (I) textos en una lengua dada con una posición determinada en la cultura correspondiente y, a su vez, (2) representación en esa lengua y cultura de otro texto previamente existente en otra lengua y con otra posición en otro sistema cultural.

Y, como primer elemento de análisis para obtener su confirmación como norma, la elección de uno de los polos ( $\mathrm{O}$-origen - o $\mathrm{M}$ - meta-) para plegarse a sus exigencias ${ }^{48}$, proceso que en caso de focalización sobre $\mathrm{O}$ se llama adecuación y en caso de preferencia por M se llama aceptabilidad (Toury 2004: 98).

Extraemos de ello que «son las normas las que determinan el tipo y grado de equivalencia

NORMAS DE TRADUCCIÓN (Toury 2004: 99-IO3)

\begin{tabular}{|l|l|l|l|l|}
\hline $\begin{array}{l}\text { I. } \\
\text { PRELIMINARES } \\
\text { (previas lógica }\end{array}$ & $\begin{array}{l}\text { Política de } \\
\text { traducción }\end{array}$ & $\begin{array}{l}\text { Elección no aleatoria } \\
\text { del tipo textual }\end{array}$ & $\begin{array}{l}\text { Condiciones de } \\
\text { tiempo y espacio }\end{array}$ & $\begin{array}{l}\text { Agentes individuales } \\
\text { o colectivos }\end{array}$ \\
\cline { 2 - 5 } las operacamente a & $\begin{array}{l}\text { Traducción } \\
\text { directa o no }\end{array}$ & $\begin{array}{l}\text { ¿Trad. indirecta } \\
\text { permitida? } \\
\text { ¿camuflada o no? }\end{array}$ & $\begin{array}{l}\text { Lenguas, tipos, } \\
\text { periodos de } \\
\text { preferencia }\end{array}$ & Lenguas intermedias \\
\hline
\end{tabular}

CON RELACIONES, INFLUENCIAS Y CONDICIONAMIENTOS MUTUOS

\begin{tabular}{|l|l|l|l|l|}
\hline \multirow{2}{*}{$\begin{array}{l}\text { 2. } \\
\text { OPERACIONALES } \\
\text { modelo de producción } \\
\text { de traducciones (base en }\end{array}$} & Matriciales $^{\mathbf{I}}$ & $\begin{array}{l}\text { Material LM para } \\
\text { la sustitución del } \\
\text { material LO }\end{array}$ & $\begin{array}{l}\text { Ubicación y } \\
\text { segmentación }\end{array}$ & $\begin{array}{l}\text { Omisiones, } \\
\text { adiciones y otras } \\
\text { manipulaciones }\end{array}$ \\
\cline { 2 - 4 } & $\begin{array}{l}\text { Lingüístico- } \\
\text { textuales }\end{array}$ & \multicolumn{2}{|l|}{\begin{tabular}{l} 
Generales (válidas para toda traducción) \\
\cline { 2 - 4 }
\end{tabular}} & \multicolumn{2}{|l|}{ Particulares (por modo de trad. o tipo textual) } \\
\hline
\end{tabular}

47 Como podemos comprobar, este tipo de afirmaciones son recurrentes y comúnmente aceptadas en los diferentes discursos surgidos en torno al canon y la censura, lo sistémico y extrasistémico, lo central y lo periférico y la dinámica que entre ellos se establece.
${ }^{4}$ Este tema se trata en estudios de traducción desde los orígenes y ha sido formulado de muy diversas formas. Un ejemplo de ellos son los conceptos de domesticación y extranjerización de los textos como dispositivos que se ponen en marcha en el proceso de traducción. 
que manifiestan las traducciones reales» (Toury 2004: I03). De este modo, Toury pretende mantener - aunque modificada, historizándola - la clásica noción de equivalencia.

Por otro lado, pueden encontrarse en una misma comunidad diferentes tipos de normas en competición según su posición en el sistema:

(I) dominantes o modernas (que ocupan el centro del sistema),

(2) previas o anticuadas (que resisten como restos arqueológicos al cambio) y

(3) nuevas o innovadoras (que empiezan a despuntar en la periferia) ${ }^{49}$. Esta clasificación es común - con ligeras modificaciones - a todas las teorías sistémicas.

Disponiendo sólo como material de trabajo de los productos ya elaborados, no podemos observar el proceso de traducción de forma directa, por lo que se impone la reconstrucción de las normas a partir de dos fuentes:

(I) textuales o primarias: textos traducidos e inventarios analíticos de traducciones; $y$

(2) extratextuales o secundarias: formulaciones teóricas y críticas, teorías prescriptivas, escritos de traductores, editores y otros agentes, evaluaciones de traducciones, de la producción de un traductor o de una escuela, etc. (Toury 2004: $107-108)^{50}$.

49 Toury alerta de que no se trata de una simple sustitución generacional, sino que las situaciones y condiciones de cambio tienden a ser más complejas.

5o Hay que prestar atención al hecho de que éstas últimas son siempre parciales y sesgadas, pueden tender a a propaganda y al sectarismo, contener vacíos y contradicciones. Conviene tomarlas como presistemáticas y considerar el estatus de cada formulación, su influencia, su prestigio y su posición en el sistema. Para ello su cotejo con las prácticas reales de traducción es fundamental. Y, a partir de él, el establecimiento de una gradación en el comportamiento traductor. (véase a este respecto el esquema de Jackson presentado por Hatim 200I: IO9-II2).

\section{PARA TERMINAR}

En respuesta a lo que hasta ahora hemos ido viendo y combinando algunas de estas interesantes teorías, en las próximas líneas se presentan, de forma sumaria y provisional, (I) una propuesta de clasificación de los mecanismos de canon/ censura, entendiendo éstos en sentido amplio, es decir, como dinámicas de inclusión/exclusión en determinado sistema y (2) una serie de prácticas dinamizadoras de la dialéctica canon/censura que suponen, a su vez, vías que la investigación en traducción literaria podría tener abiertas en torno al estudio de cánones y censuras.

\section{I Propuesta de clasificación de los mecanismos de canonización/censura}

Entendiendo, como se ha dicho anteriormente, la dinámica entre canonización y censura como cara y cruz del mismo mecanismo de inclusión y exclusión en el sistema, y - yendo más allá de la jerarquía de poderes que entre los elementos del sistema pueda establecerse, algo que habrá que estudiar caso por caso- tomemos ahora el esquema de los elementos y relaciones del sistema literario que se expuso unas páginas atrás a propósito de las teorías polisistémicas (Even-Zohar).

De los textos estudiados - especialmente los de Lefevere y Bourdieu- podemos deducir que hay razones para pensar que institución, mercado y repertorio son los elementos reguladores de la entrada y salida de textos en el sistema literario, por tanto pueden ser considerados agentes de canonización y censura. Pero lo hacen a través de los procedimientos que le son propios, aunque éstos estén interrelacionados, de modo que podemos hablar de tres tipos de mecanismo de canonización/censura:

I. Canonización / censura institucional,

2. canonización / censura del mercado y

3. canonización / censura del repertorio. 
I) E1 mecanismo institucional puede a su vez ejercerse desde tres ámbitos: (a) aca208 démico, cuya herramienta son los procesos de instrucción; (b) crítico, cuya herramienta es la prensa y (c) censura institucional propiamente dicha, creada con la función expresa de administrar el control sobre el sistema cultural y no siempre centralizada (un caso de descentralización puede ser el mecenazgo de las subvenciones, que en estados no totalitarios no siempre se regula de forma homogénea y transparente).

2) El mecanismo de canonización / censura del mercado, es el que depende en última instancia del beneficio económico derivado del intercambio mercantil. En él entran en juego las editoriales, la publicidad y promoción por ellas fabricadas para hacer atractivos sus productos, la regulación de derechos de autor... Su censura es sorteada especialmente por los bestsellers (Bourdieu) creados ad hoc para superar su barrera.

3) Impone su freno a los elementos inclasificables — sin referente teórico-, irreconocibles - pertenecientes a sistemas extraños al de acogida- e innovadores, aún no reconocidos por la tradición - memoria (Lotman) - o bien en desuso —olvido (Lotman)-.

Entre estos tres mecanismos se dan con frecuencia relaciones de dependencia - por ejemplo, la de la censura de mercado (2), la censura académica (ra) y la censura crítica ( $\mathrm{Ib}$ ) respecto a la censura institucional propiamente dicha (Ic) en los estados totalitarios cuyo mercado está subordinado a intereses ideológicos- $\mathrm{e}$ interdependencia y connivencia más o menos reconocida - por ejemplo entre las editoriales (2) y la crítica (Ib).

Es claro que en los sistemas políticos totalitarios tendrá preeminencia en la jerarquía la

censura institucional propiamente dicha (Ic) y en los sistemas democráticos de corte neoliberal este lugar lo ocupará el mercado (2).

Por supuesto, no hay que olvidar que estos mecanismos son modelados por (a) las interrelaciones de sus elementos, (b) por la presencia de elementos ambivalentes (Lotman) y (c) por las mutantes posiciones jerárquicas de ciertos mecanismos - y su sistema correspondiente: político, educativo, comercial...- mas sus correspondientes herramientas con respecto a otros. Además, esta flexibilidad es mayor en momentos de transición y desequilibrio entre los elementos que conforman el sistema y menor en sus momentos de mayor estabilidad.

Una de las prácticas de desestabilización más potentes es precisamente la que «obliga» al sistema literario o cultural a dialogar con un sistema ajeno a él a través de la introducción de nuevos productos - textos, en este caso-, y es precisamente el tema que nos ocupa: la práctica traductora, que puede reproducir, validar, modificar o cuestionar a través de la acción cultural -es decir, no sólo a nivel teórico- la naturaleza y jerarquía de tales relaciones.

\subsection{Prácticas dinamizadoras de la dialéctica canon/censura en literatura}

Dicho esto y partiendo de una posición de rechazo del anquilosamiento del canon - si bien no cabe duda de la importancia y riqueza de su conservación y cultivo como tradición y modulador de identidades culturales-, podemos enumerar una serie de prácticas desestabilizadoras y, por consiguiente, dinamizadoras de la dialéctica canon / censura en campo literario que favorecen el diálogo entre diferentes sistemas, introducen vínculos imprevisibles y desautomatizan el sistema: 


\section{Ia. Escuela y ámbito académico}

(I) proponer textos no canónicos al alumnado;

(2) favorecer el diálogo con interpretaciones y formas de comentario (Kermode) alternativas a las canónicas o

(3) instar a los alumnos a la construcción de su propio canon personal para evidenciar su artificialidad.

\section{Ib. Crítica y traducción - reescrituras (Lefevere)}

(I) proponer reinterpretaciones críticas o interpretaciones alternativas —activación de diferentes valencias de sentido- de obras canónicas;

(2) recuperar textos, autores y modelos desplazados o ignorados por el sistema (canon) o

(3) denunciar la connivencia de sectores de poder de la crítica con importantes editoriales.

\section{Mercado editorial -el espacio de acción más difícil,} pues dados su poder e intereses económicos pondrá en marcha espontáneamente sus mecanismos de censura derivados de la falta de beneficio-:

(I) creación y promoción de antologías y colecciones introductoras de textos extrasistémicos (periféricos, olvidados por la tradición...);

\section{Repertorio - disciplinas consagradas a su análisis}

(Semiótica de la Cultura, Traductología, Literatura Comparada...)—:

(I) creación de metalenguajes para la descripción e historiografía de elementos extrasistémicos proporcionándoles existencia;

(2) reconstrucción de los procedimientos de constitución del canon y los mecanismos de censura y

(3) evidenciación de los intereses y relaciones de poder que los regulan, sanando así la «amnesia de la génesis» (Bourdieu) y cuestio- nando los valores inamovibles del totalitario canon trascendental.

RECIBIDO EN DICIEMBRE 2006

\section{BIBLIOGRAFÍA}

Benjamin, W. (I990) «La obra de arte en la época de su reproductibilidad técnica», Discursos interrumpidos I, Madrid, Taurus, pp.15-6o.

Bloom, H. (2002) El canon occidental. La escuela y los libros de todas las épocas. Barcelona, Anagrama. Traducción de inglés de Damián Alou (The Western Canon. The Books and School of the Ages)

Bourdieu, P. (1979) La distinction. Critique sociale du jugement, Paris, Les éditions de Minuit.

(2002) Las reglas del arte. Génesis y estructura del campo literario, Barcelona, Anagrama.

Eagleton, T. (1998) Walter Benjamin o hacia una crítica revolucionaria. Madrid, Cátedra - Teorema. Traducción del inglés de Julia García Lenberg (Walter Benjamin or towards a Revoltionary Criticism).

Eco, U. (I997) Interpretación y sobreinterpretación. Madrid. CUP (Cambridge University Press). Traducción de Juan Gabriel López Guix.

Even-Zohar, I. (I994) «La función de la literatura en la creación de las naciones de Europa» en Darío Villanueva (comp) Avances en teoría de la literatura. Estética de la recepción, Pragmática, Teoria empirica y Teoría de los polisistemas. Santiago. Universidad de Santiago de Compostela.

(1997) «Factores y dependencias en la cultura. Una revisión de la teoría de los polisistemas» en Iglesias Santos, M. (coord.) Teoría de los polisistemas (1999), Madrid, Arcolibros.

Foucault, M. (1999) Entre filosofía y literatura, Barcelona, Paidós.

Gnisci, A. coord. (2002) Letteratura Comparata. Milán. Bruno Mondadori.

Hatim, B. (200I) Teaching and Researching Translation, Harlow, Longman.

- y Mason, I. (I995) Teoría de la traducción. Una aproximación al discurso. Barcelona, Ariel. Traducción del inglés de Salvador Peña (Discourse and the Translator, 1990) 
Horkheimer, M. y Adorno, T. W. (200I) Dialéctica de la ilustración, Madrid, Trotta.

Hurtado Albir, A. (200I) Traducción y Traductología. Introducción a la traductología. Madrid, Cátedra.

210 Iglesias Santos, M. (I999) «La teoría de los polisistemas como desafío a los estudios literarios» en Teoría de los polisistemas (1999), Madrid, Arcolibros.

Lambert, J (I99I) «Literatura, traducción y (des) colonización» en Teoría de los polisistemas (I999), Madrid, Arcolibros.

Lefevere, A. (1997) Traducción, reescritura y manipulación del canon literario, Madrid, Casa de España. Traducción del inglés de Carmen África Vidal Claramonte y Román Álvarez (Translation, Rewriting and the Manipulation of Literary Fame, I992)

Lotman, (vol.r: 1996, vol. 2: 1998, vol. 3: 2000) La semiosfera (3 volúmenes), Madrid, Cátedra - Frónesis, Universidad de Valencia. Traducción del ruso de Desiderio Navarro.

Méndez Rubio, A. (1997) Encrucijadas. Elementos de crítica de la cultura, Madrid, Cátedra - Frónesis, Universidad de Valencia.
Morillas, E. y Arias, J. P. (coord.)(1997) El papel del traductor, Madrid, Casa de España.

Robbins, Derek (2000) Bourdieu and Culture, London SAGE Publications.

Payne, M. (comp.) (2002) Diccionario de teoría crítica y estudios culturales. Buenos Aires, Paidós. Traducción del inglés de Patricia Willson (A Dictionary of Cultural and Critical Theory, 1996)

Peña, S. y Hernández Guerrero, M. J. (I994) Traductología. Málaga. Universidad de Málaga, Servicio de Publicaciones e Intercambio Científico.

Pozuelo Yvancos, José Ma (1995) «El canon en la teoría literaria contemporánea», Eutopias, vol. Io8, Valencia, Episteme.

Talens, J. (1993) El sentido Babel, Valencia, Eutopías.

- - (I994) Escritura contra simulacro, Valencia, Eutopías.

Toury, G. (2004) Los estudios descriptivos de traducción y más allá. Metodología de la investigación en estudios de traducción, Madrid, Cátedra. Traducción del inglés de Rosa Rabadán y Raquel Merino (Descriptive Translation Studies and Beyond, I995) 